\title{
Neural Circuit in the Dorsal Raphe Nucleus Responsible for Cannabinoid-Mediated Increases in 5-HT Efflux in the Nucleus Accumbens of the Rat Brain
}

\author{
Rui Tao and Zhiyuan Ma \\ Charles E. Schmidt College of Medicine, Florida Atlantic University, Boca Raton, FL 33431, USA
}

Correspondence should be addressed to Rui Tao, rtao@fau.edu

Received 5 April 2012; Accepted 29 May 2012

Academic Editors: G. A. Gudelsky and D. K. Miller

Copyright (C) 2012 R. Tao and Z. Ma. This is an open access article distributed under the Creative Commons Attribution License, which permits unrestricted use, distribution, and reproduction in any medium, provided the original work is properly cited.

\begin{abstract}
In vivo microdialysis was used in this study to reveal the role of cannabinoids in regulating serotonin (5-HT) efflux in the nucleus accumbens (NAcc) and dorsal raphe nucleus (DRN). The cannabinoid CB1 receptor agonists WIN55212-2 and CP55940 systematically administered to rats caused significant increases in 5-HT efflux in the NAcc but failed to have an effect in the DRN. To reveal mechanisms underlying regionally selective responses, we tested the hypothesis that cannabinoids have both direct and indirect effects on 5-HT efflux, depending on the location of CB1 receptors in the neural circuit between DRN and NAcc. We showed that the direct effect of cannabinoids caused a reduction in 5-HT efflux whereas the indirect effect resulted in an increase. Furthermore, the indirect effect was blocked by the $\mathrm{GABA}_{\mathrm{A}}$ receptor antagonist bicuculline in the DRN, suggesting that the action is likely due to a presynaptic inhibition on GABAergic activity that exerts a tonic influence on neuronal circuits regulating 5HT efflux. Involvement of GABAergic neurons was confirmed by measuring changes in GABA efflux. Taken together, our study suggests that cannabinoids may have direct and indirect effects on the 5-HT regulatory circuits, resulting in regionally selective changes of 5-HT efflux in the brain.
\end{abstract}

\section{Introduction}

Cannabinoid CB1 receptors and relevant endocannabinoids are widely distributed throughout the brain in mediating affective, cognitive, and motor behaviors $[1,2]$. Much of the current neurochemical evidence suggests that their functional roles are mainly to modulate presynaptic neurotransmission impinging on postsynaptic neurons [3-6]. Midbrain raphe serotonergic neurons are known as an important substrate of cannabinoids, which have been demonstrated operating in a plethora of neurological responses [6-9]. Thus, the explicit understanding of cannabinoid modulations on midbrain raphe serotonergic neuronal activity has been for many years one of the central issues in the cannabinoid research.

The dorsal (DRN) raphe nuclei (MRN) are two principal sources of serotonergic projections to the forebrain. The DRN serotonergic projections are likely associated with cognitive and affective activity $[10,11]$ while MRN serotonergic neurons are more clinging to motor behavior [12, 13]. Some of the forebrain neurons, particularly GABAergic and glutamatergic afferents, in turn innervate raphe nuclei forming feedback circuits that control extreme fluctuations of 5-HT availability [14]. The convergence of evidence suggests that GABAergic and glutamatergic afferents put different weights on controlling serotonergic activity in two raphe nuclei. GABAergic afferents have a strong and tonic inhibitory influence on serotonergic neurons in the DRN but little to the MRN [15-17]. However, less is known about the fundamental mechanism underlying neural circuit used by cannabinoids for 5-HT release in the forebrain.

The primary goal of the present study was to determine how 5-HT efflux in somatodendritic and axon terminal regions is altered differently in response to administrations of cannabinoids. This study was carried out in the DRN and one of serotonergic ascending projection sites, namely, 
nucleus accumbens (NAcc). The second goal was to test the hypothesis that there are direct and indirect effects of cannabinoids on 5-HT efflux in the NAcc. Specifically, the direct effect is simply to inhibit axonal terminal activity via the activation of $\mathrm{CB} 1$ receptors, resulting in reduction in 5-HT efflux. In contrast, the indirect effect is to disinhibit postsynaptic 5-HT neurons at the DRN involving in GABAergic neurotransmission, resulting in an increase in 5-HT efflux. Our results clearly support a conclusion that when cannabinoids are administered systemically in freely behaving animals, the actual 5-HT efflux is determined by the net effect of two opposite actions, resulting in only a small increase in 5-HT efflux in the NAcc.

\section{Materials and Methods}

2.1. Animal Preparation. Adult male Sprague-Dawley rats purchased from Charles River Laboratories (Raleigh, NC, USA) were pair housed with food and water available ad libitum in a temperature- and humidity-controlled facility and were maintained on a $12 \mathrm{~h}$ light/dark cycle (lights on at 08:00 AM). All animal use procedures were in strict accordance with the National Institutes of Health Guide for the Care and Use of Laboratory Animals, and the study was specifically approved by the Institutional Animal Care \& Use Committee at Florida Atlantic University (Permit number/ID: A10-05). Rats weighing from 300 to $350 \mathrm{~g}$ were anesthetized with a combination of xylazine $(4 \mathrm{mg} / \mathrm{kg}$ i.p.) and ketamine ( $80 \mathrm{mg} / \mathrm{kg}$ i.p.), and then guide cannulae (21gauge stainless steel tubing) were preimplanted as described previously in detail using standard techniques for stereotaxic surgery [18]. The coordinates for guide cannulae in the DRN were AP 1.2 relative to interaural zero, ML 4.0, and DV 1.0 below the skull surface at a $32^{\circ}$ angle lateral to midline; and in the NAcc, AP 10.7, ML 1.4, and DV 1.0 below the skull surface [19]. After implantation, the guide cannulae were plugged with obturators for protection. The animals were allowed a recovery period of at least 1 week before microdialysis.

2.2. Microdialysis. The evening before the experiments, rats were briefly anesthetized with isoflurane, and aseptic dialysis probes were inserted through the guide cannulae. The target coordinates for the tip of the probe were as follows: in the DRN, AP $1.2 \mathrm{~mm}$ relative to interaural zero, ML $0.6 \mathrm{~mm}$ relative to midline, and DV $5.5-6.4 \mathrm{~mm}$ below the skull surface; in the NAcc, AP $10.7 \mathrm{~mm}$, ML $1.4 \mathrm{~mm}$, and DV 6.0$8.5 \mathrm{~mm}$. Rats were then placed in a test chamber and attached to a fluid swivel that allowed animals to move freely. Food and water were available ad libitum. Dialysis probes were perfused overnight with artificial cerebrospinal fluid (aCSF) containing $140 \mathrm{mM} \mathrm{NaCl}, 3.0 \mathrm{mM} \mathrm{KCl}, \quad 1.5 \mathrm{mM} \mathrm{CaCl}_{2}$, $1.0 \mathrm{mM} \mathrm{MgCl}_{2}, 0.25 \mathrm{mM} \mathrm{NaH}_{2} \mathrm{PO}_{4}$, and $1.0 \mathrm{mM} \mathrm{Na}_{2} \mathrm{HPO}_{4}$. The aCSF was pumped at a rate of $1.0 \mathrm{uL} / \mathrm{min}$. Samples were collected manually, beginning at 10:00 am the following day. Samples were collected at 30-min intervals and analyzed by high-performance liquid chromatography with electrochemical detection (HPLC-EC; EiCOM HTEC-500) in conjugation with an autoinjector (CMA 200). In the 5 -HT assay, mobile phase $(0.1 \mathrm{M}$ phosphate buffer at $\mathrm{pH}$ $6.0,500 \mathrm{mg} / \mathrm{L} 1$-decanesulfonic acid, $50 \mathrm{mg} / \mathrm{L}$ EDTA, and $1.0 \%$ methanol) was pumped at a rate of $0.50 \mathrm{~mL} / \mathrm{min}$. In the GABA assay, samples were prederivatized with $o_{-}$ phthaldialdehyde and 2-methy-2-propanethiol for $10 \mathrm{~min}$ at room temperature and then analyzed on a C18 column $(100 \times 3.2 \mathrm{~mm}, \mathrm{BASi}$, USA $)$. The mobile phase consisted of $40 \%$ acetonitrile, $0.1 \mathrm{M}$ sodium acetate buffer, and $50 \mathrm{mg} / \mathrm{L}$ EDTA at pH 6.0 [20]. The flow rate of GABA separation was set at $0.7 \mathrm{~mL} / \mathrm{min}$.

2.3. Procedures of Drug Administration. To investigate the neural circuit involving in CB1 receptors, drugs were examined by administering to rats through two distinct routes: systemic administration and local infusion. For the systemic administration, WIN 55,212-2, CP 55940, AM251, and SR 147778 being dissolved in saline containing 10\% Tween80 and $20 \%$ dimethyl sulfoxide (DMSO) were injected intraperitoneally at a volume of $1 \mathrm{~mL} / \mathrm{kg}$ in body weight. WIN 55,212-2 mesylate and AM251 were purchased from Tocris Cookson (Ellisville, MO, USA). CP 55940, Tween80, and DMSO were purchased from Sigma (St. Louis, MO, USA). SR 147778 was obtained from Sanofi-Synthelabo (Paris, France). Control animals were administered with the vehicle that was used to dissolve the drugs. For the local infusion, drugs dissolved in the infusion medium were delivered directly into the DRN or NAcc. Except for experiments in Figure 3, WIN 55,212-2 was usually dissolved in the artificial cerebrospinal fluid (aCSF) containing 1.5\% ethanol and $1.5 \%$ cremophor. Cremophor and ethanol were purchased from Sigma. In Figure 3, WIN 55,212-2 was dissolved in the aCSF containing $1 \mu \mathrm{M}$ citalopram in addition to $1.5 \%$ ethanol and $1.5 \%$ cremophor. Note that the purpose of this set of experiments was to test whether cannabinoids could directly inhibit 5-HT efflux released from dendrites in the DRN or from axon terminals in the NAcc. However, 5-HT basal release was already low in the regular microdialysis samples at which an inhibitory response to drugs is not easily detected by measuring reduction in 5-HT efflux. Thus, citalopram, a selective serotonin reuptake inhibitor (SSRI), was employed to elevate the baseline so that reduction in 5-HT efflux, if any, could be reliably measured with the microdialysis approach. Previous studies have demonstrated that citalopram added into the infusion medium at the concentration of $1 \mu \mathrm{M}$ would not alter the quality of the drug response [21]. Lastly, bicuculline at the concentration of $100 \mu \mathrm{M}$ was dissolved in the aCSF before infusing into the DRN. Bicuculline was purchased as the methobromide$\mathrm{H}_{2} \mathrm{O}$ salt from Tocris Cookson (Ellisville, MO, USA). In the control animals, the DRN or NAcc was locally infused with the vehicle (isotonic) that was used to dissolve the drugs.

2.4. Data Analysis. To reduce intersubject variability in group analysis, the data presented in figures are expressed as mean ( \pm S.E.M.) percentage of changes from averaged baseline measurements. Mean baseline 5-HT levels were calculated as the average of four successive samples before 
drug administration. Statistical analysis was performed by the two-way (drug treatment $\times$ time) factorial ANOVA. If significant interactions of drug treatment $\times$ time course were found, further statistical analysis was carried out using the one-way ANOVA followed by post hoc Scheffe test in determining the significance of the respective time points. The level of $P$ value was set at 0.05 for a statistically significant effect.

\section{Results}

The first set of experiments was to determine whether systemic injection of WIN 55,212-2 (WIN55 hereafter) had an effect on 5-HT efflux in the brain. The doses used in this study were based on behavioral investigations at which the drug was effective to produce conditioning place preference $[22,23]$. As shown in Figure 1(a), WIN55 at 2.5 and $5 \mathrm{mg} / \mathrm{kg}$ (i.p.) failed to elicit a significant effect on extracellular 5-HT in the DRN. The conclusion was supported by the two-way ANOVA test revealing that there was no significant effect of treatment doses $\left(F_{\text {dose }}(2,21)=1.598, P=0.2258\right)$, time $\left(F_{\text {time }}(5,105)=1.324, P=0.2599\right)$, or interaction of time $\times$ doses $\left(F_{\text {int }}(10,105)=0.54, P=0.8583\right)$. In contrast, the same injection produced a dose- and time-dependent increase in the NAcc (Figure 1(b); $F_{\text {dose }}(2,26)=11.854$, $\left.P=0.0002 ; F_{\text {time }}(5,130)=5.766, P=0.0002\right)$. The post hoc Scheffe test showed that the significant effect was apparent 30 min after injection.

CP55940 (CP55 hereafter), which is known for its high affinity to bind cannabinoid receptors [24], was used to reexamine the NAcc response to cannabinoid injection. The dose used in this study was $0.25 \mathrm{mg} / \mathrm{kg}$ and $0.5 \mathrm{mg} / \mathrm{kg}$. CP55 at $0.5 \mathrm{mg} / \mathrm{kg}$ produced over $50 \%$ increases in the NAcc (Figure 1(c)) but not in the DRN (data not shown). The ANOVA test revealed a significant effect of drug doses $\left(F_{\text {dose }}(2,24)=7.185, P=0.0036\right)$ and time $\left(F_{\text {time }}(5,120)=\right.$ $6.766, P=0.0001)$. The post hoc Scheffe test showed that the significant increase occurred between 0.5 and $1.5 \mathrm{~h}$ after the injection.

Next, we tested whether the WIN55-induced increases in 5-HT efflux in the NAcc could be attributable to the activation of CB1 receptors. SR 147778 is a newly synthesized chemical that has a highly potent antagonistic activity at CB1 receptors [25, 26]. As shown in Figure 2(a), SR 147778 $(5 \mathrm{mg} / \mathrm{kg}$, i.p.) alone had no effect on $5-\mathrm{HT}$ in the NAcc. Injection of SR $14777830 \mathrm{~min}$ before WIN55 ( $5 \mathrm{mg} / \mathrm{kg}$ i.p.) blocked the WIN55-evoked increases in 5-HT efflux in the $\operatorname{NAcc}\left(F_{\text {treatment }}(1,9)=9.457, P=0.0132\right)$. This observation was reaffirmed with AM251, a conventional CB1 receptor antagonist [6]. Similarly, AM251 alone had no effect on 5-HT efflux. AM251 pretreatment 30 min before WIN55 significantly blocked the WIN55-elicited increases in 5-HT in the NAcc (Figure 2(b); $F_{\text {treatment }}(1,11)=31.804, P=$ 0.0002).

It has been suggested that endogenous opioidergic system may be one of the substrates responsible for the effect of CB1 receptor agonists in the CNS [27-29]. Since opioids also cause regional selective effects on 5-HT efflux [30], we tested whether endogenous opioids are involved in the WIN55induced increases in 5-HT in the NAcc. If this was the case, the opioid receptor antagonist naloxone should be able to antagonize the effect. As shown in Figure 2(c), naloxone alone $(10 \mathrm{mg} / \mathrm{kg}$, s.c.) had no effect on 5-HT efflux. Naloxone pretreatment failed to block the WIN55-induced increases in 5-HT efflux $\left(F_{\text {treatment }}(1,14)=1.579, P=0.2295\right)$, suggesting that endogenous opioids did not mediate the effect of cannabinoids on 5-HT efflux.

We suggest that the existence of a neural circuit is responsible for regional selective effects of cannabinoids on 5-HT efflux in the CNS. To test this hypothesis, cannabinoids were directly applied to the DRN or NAcc through microdialysis probes while 5-HT efflux was determined using the same probes. In this set of experiment, $1 \mu \mathrm{M}$ citalopram was included into the infusion medium to elevate the basal levels of 5-HT efflux. Note that citalopram at such a low concentration would not alter the response of serotonergic neurons to drug administration [21]. As shown in Figure 3(a), WIN55 at 100, 300, and $1000 \mu \mathrm{M}$ infusing into the DRN produced a robust increase in 5-HT efflux in a concentration-dependent manner $\left(F_{\text {dose }}(3,19)=5.273, P=\right.$ $0.0081)$. In contrast, WIN55 infusion directly into the NAcc caused a concentration-dependent reduction in 5-HT efflux in the NAcc (Figure 3(b); $F_{\text {dose }}(3,20)=5.219, P=0.008$ ).

Thus, WIN55 produced two opposite effects on 5-HT efflux in the NAcc, depending on the route of drug administrations. We suggest that the systemic WIN55-induced increases may be due to disinhibition of serotonergic neurons in the DRN. If this was the case, we expected that local infusion of WIN55 to the DRN would also elicit an increase in 5-HT in the NAcc, similar to the systemic injection. To test this, we employed a dual-probe microdialysis technique. As shown in Figure 4(a), WIN55 infusion into the DRN caused a concentration-dependent increase in the NAcc $\left(F_{\text {dose }}(2,18)=4.256, P=0.0307\right)$. Based on evidence that the direct effect of cannabinoids is inhibitory [31, 32 ], we further suggest that the WIN55-induced increases may be due to inhibition of GABAergic neurotransmission on the serotonergic neurons in the DRN. If this was the case, bicuculline, a $\mathrm{GABA}_{\mathrm{A}}$ receptor antagonist, locally infusing into the DRN would block the inhibitory impact of GABAergic neurotransmission and thereby disrupt the effect of WIN55 on the increased 5-HT efflux. As shown in Figure 4(b), bicuculline pretreatment in the DRN abolished the systemic WIN55 $(5 \mathrm{mg} / \mathrm{kg}$, i.p)-elicited increases in 5-HT efflux in the NAcc $\left(F_{\text {treatment }}(1,14)=3.153, P=0.0975\right)$.

Lastly, to confirm the relationship between GABAergic presynaptic responses and cannabinoid administration, we measured changes in GABA efflux in the DRN. As shown in Figure 5, there was a significant reduction in GABA efflux in the DRN following injection of WIN55 and CP55 $\left(F_{\text {treatment }}(2,13)=43.843, P<0.0001\right)$.

\section{Discussion}

By measuring changes in 5-HT and GABA efflux in the DRN and/or NAcc, this present study demonstrated that there 


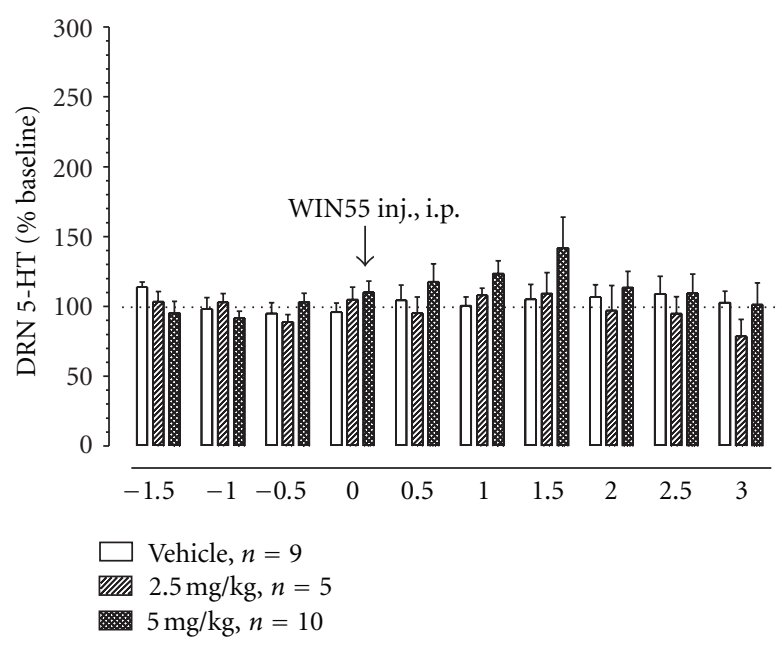

(a)

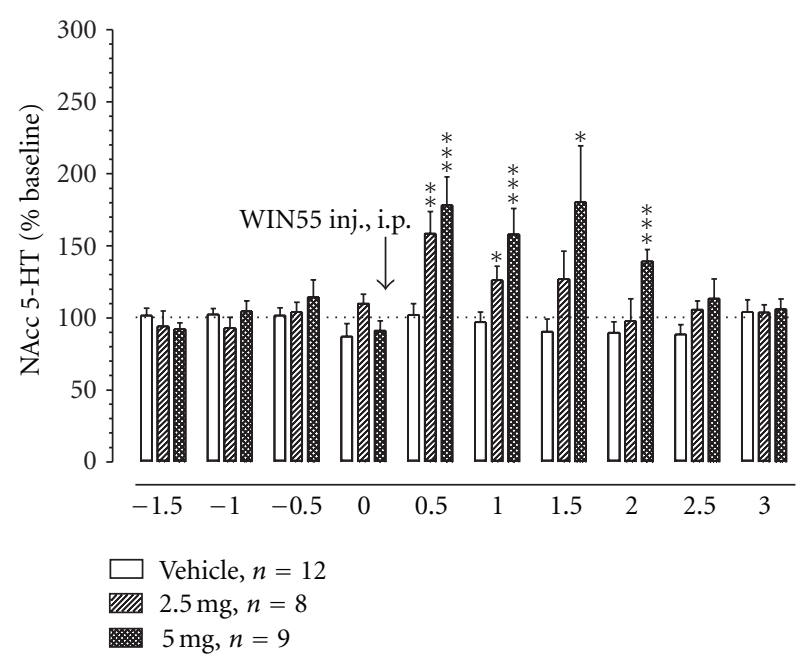

(b)

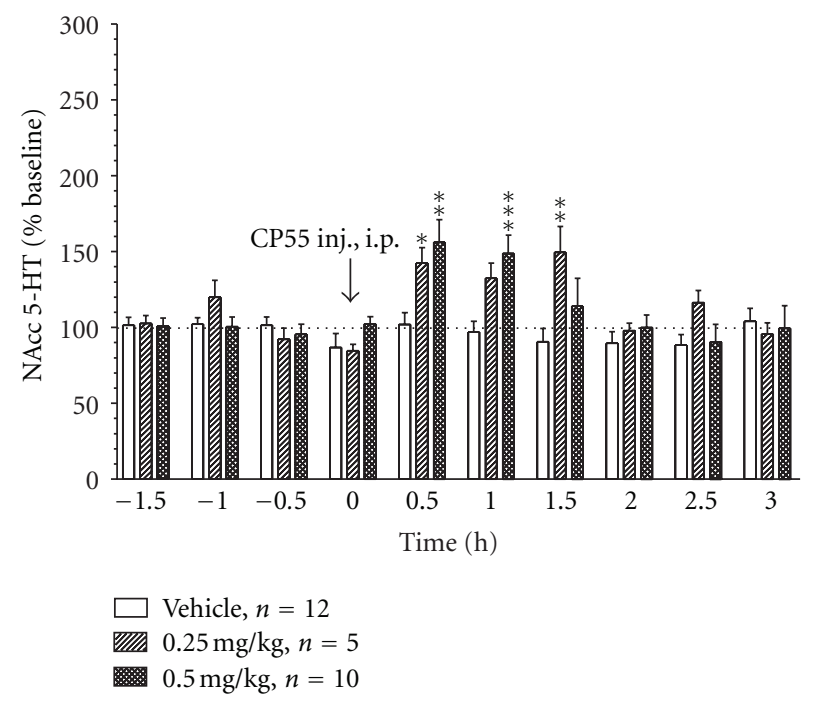

(c)

FIgURE 1: Systemic effect of CB1 receptor agonists on 5-HT efflux in the DRN and NAcc. Data are expressed as percent of average baseline values (\% mean \pm s.e.m.). Mean baseline level of extracellular $5-\mathrm{HT}$ was $0.62 \pm 0.02 \mathrm{pg} / \mathrm{sample}$ in the DRN $(n=24)$ and $0.31 \pm 0.01 \mathrm{pg} / \mathrm{sample}$ in the NAcc $(n=44)$. The arrow indicates the time of the injection. (a) Systemic injection of WIN 55,212-2 (2.5 and $5 \mathrm{mg} / \mathrm{kg}$, i.p.) had no effect on extracellular 5-HT in the DRN. (b) Systemic injection of WIN 55,212-2 (2.5 and $5 \mathrm{mg} / \mathrm{kg}$, i.p.) produced dose- and time-dependent effects on extracellular 5-HT in the NAcc. (c) Systemic injection of CP55940 (0.25 and $0.5 \mathrm{mg} / \mathrm{kg}$, i.p.) produced dose- and time-dependent effects on extracellular 5-HT in the NAcc. ${ }^{*} P<0.05$ and ${ }^{* * *} P<0.001$ versus vehicle examined by the repeated measures ANOVA followed by the post hoc Scheffe test.

exists a neural circuit in the DRN through which cannabinoids regulate serotonergic neuronal activity in the NAcc. Our data provide evidence demonstrating that cannabinoids can exert both indirect and direct effects on serotonergic neurons; the direct effect of cannabinoids is inhibitory while the indirect effect via presynaptic circuit is excitatory. Despite having opposite effects, we showed that systemic administration of exogenous cannabinoids such as WIN55 and CP55 has a modest excitatory net effect on 5-HT efflux in the NAcc of drug-naïve animals. This is consistent with the reports that the neurophysiologic function of cannabinoids is considered to be a neuromodulator that usually exerts their effect on both local principal neurons and all types of afferents $[6,32,33]$, resulting in a site-specific response [34].

In the DRN, GABAergic and glutamatergic components are two major afferents that synapse onto the serotonergic neurons, controlling 5-HT availability for the forebrain [14, 35]. CB1 receptors are found to be widely expressed in 


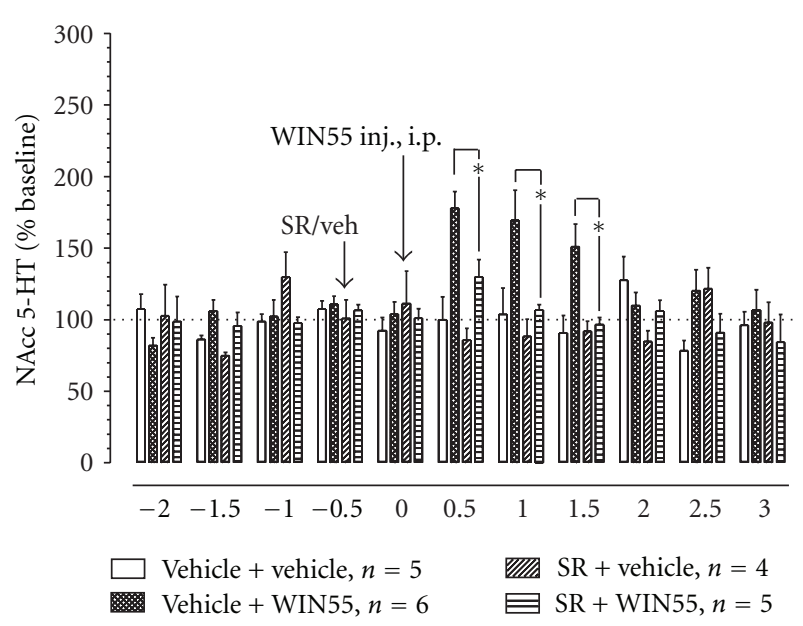

(a)

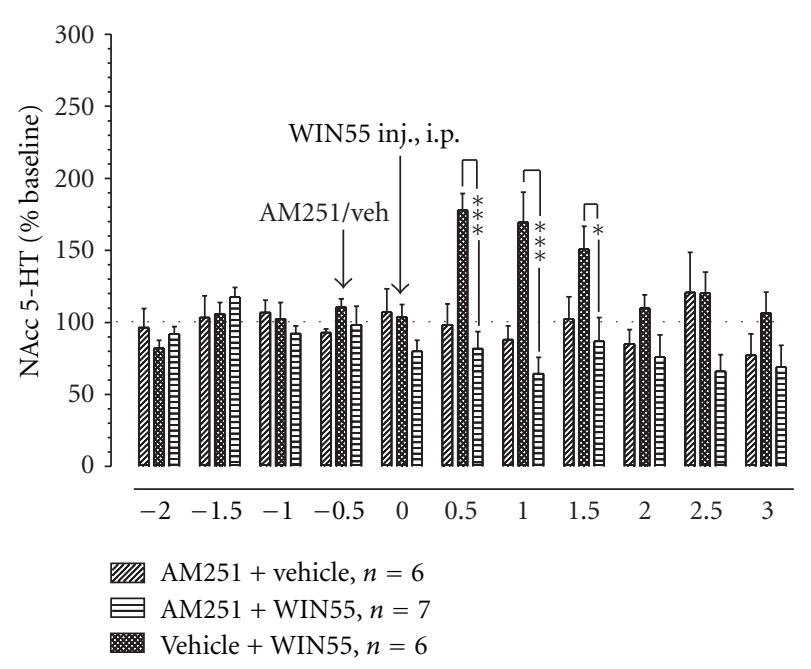

(b)

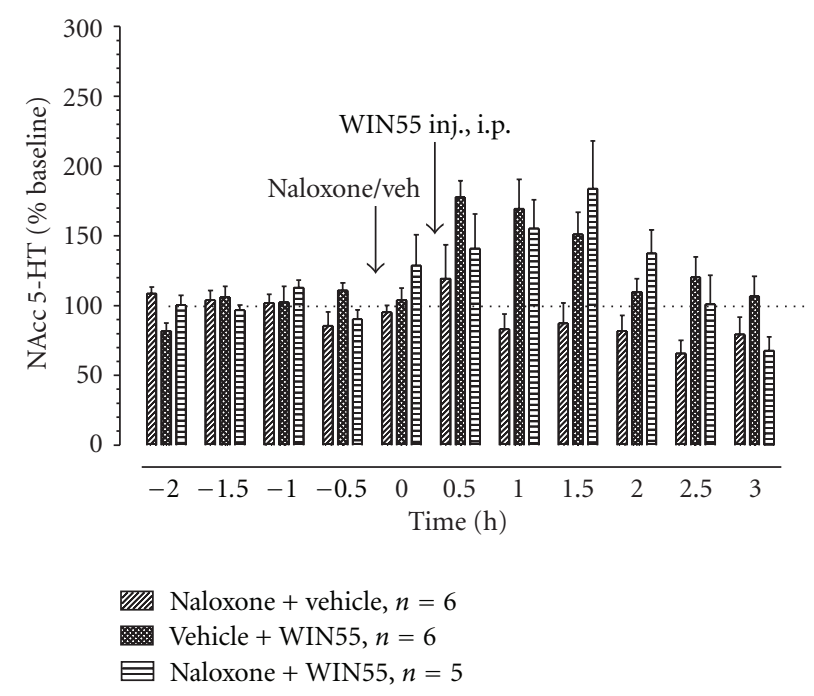

(c)

FIGURE 2: Effects of CB1 and opioid receptor antagonists on WIN 55,212-2-induced increases in 5-HT in the nucleus accumbens. Data are expressed as percent of average baseline values (\% mean \pm s.e.m.). Mean baseline level of extracellular 5-HT was $0.39 \pm 0.04 \mathrm{pg} / \mathrm{sample}$ in the NAcc $(n=45)$. The arrows indicate the time of injection of antagonists 30 min before WIN 55,212-2. The effect of WIN 55,212-2 on 5-HT efflux in the NAcc was blocked by SR 147778 (5 mg/kg i.p.; (a)) and AM251 (5 mg/kg, i.p; (b)), but not by naloxone (10 mg/kg, s.c.; (c)). ${ }^{*} P<0.05$ and ${ }^{* * *} P<0.001$ versus vehicle examined by the repeated measures ANOVA followed by post hoc Scheffe test.

the raphe afferents [6] in addition to serotonergic cells [9]. Thus, cannabinoids can exert their effects on all regulatory afferents and principal neurons that form a neural circuit including GABAergic, glutamatergic, and serotonergic components. As such, the change in 5-HT efflux in response to systemic cannabinoids cannot be exclusively a result of the direct action on serotonergic neurons but a complicated integration of inhibitory modulation of both inhibitory and excitatory neurotransmissions impinging on postsynaptic serotonergic neurons. Thus, the effect of cannabinoids on 5HT release would be a compromised result of excitatory and inhibitory influences, which may explain the findings that there were only modest changes in 5-HT efflux observed in the present study.

The present findings that cannabinoids exert both direct and indirect effects on serotonergic neurons are well consistent with the previous reports that cannabinoids can either reduce [36, 37], elevate $[38,39]$, or bidirectionally alter serotonergic activity [8]. Theoretically, the inhibition of glutamatergic afferents would cause a reduction in 5-HT efflux while the inhibition of GABAergic afferents would result in an increase in 5-HT efflux. Therefore, their net effects on serotonergic neurons are likely determined by their relative potency of tonic activity. Physiologically, GABAergic 


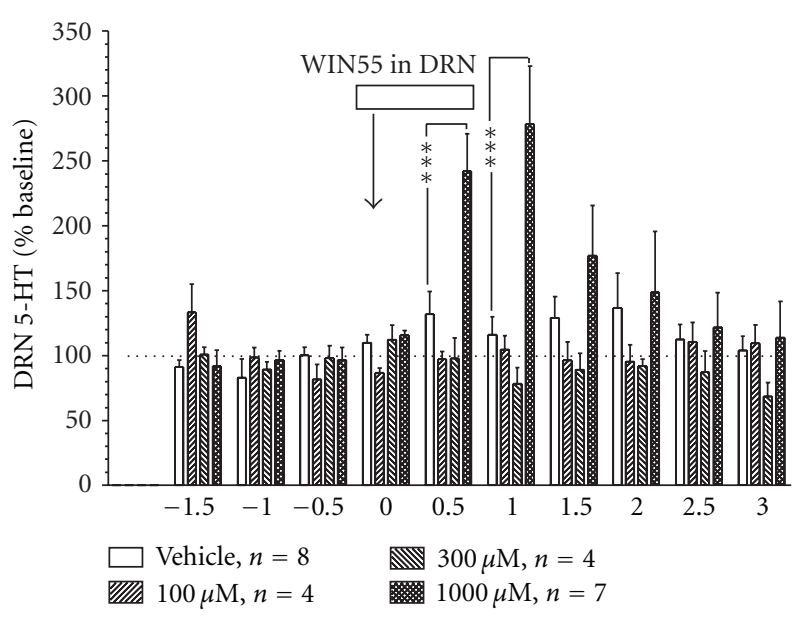

(a)

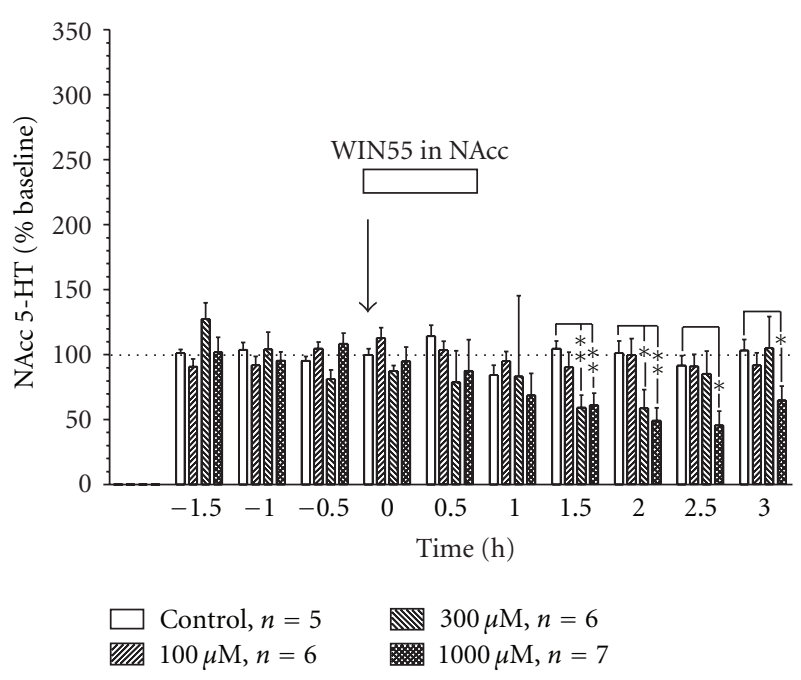

(b)

FIGURE 3: Effect of reverse dialysis infusion of WIN 55,212-2 on 5-HT efflux in the DRN (a) or NAcc (b). Data are expressed as percent of average baseline values (\% mean \pm s.e.m.). Note that $1 \mu \mathrm{M}$ citalopram was included in the infusion medium. Mean baseline level of extracellular 5 -HT was $3.35 \pm 0.06 \mathrm{pg} / \mathrm{sample}$ in the DRN $(n=23)$ and $4.15 \pm 0.79 \mathrm{pg} / \mathrm{sample}$ in the NAcc $(n=24)$. The open horizontal bars indicate the 30-min period of drug infusion. (a) WIN 55,212-2 (100, 300 and $1000 \mu \mathrm{M})$ produced a concentration-dependent increase in 5-HT efflux in the DRN. (b) WIN 55,212-2 (100, 300, and $1000 \mu \mathrm{M})$ produced a concentration-dependent decrease in 5-HT efflux in the NAcc. ${ }^{*} P<0.05,{ }^{* *} P<0.01$ and ${ }^{* *} P<0.001$ versus vehicle examined by the repeated measures ANOVA followed by post hoc Scheffe test.

afferents exert spontaneous inhibitory tone on serotonergic neurons while glutamatergic afferents almost have no measurable role in terms of spontaneous action. Note that spontaneous action of glutamatergic afferents is apparent only at a specific behavioral state such as responding to auditory stimulation [40]. Therefore, it is conceivable that modulation of GABAergic afferents would be more prominent on 5-HT efflux than the glutamatergic influence. In general, presynaptic modulation of GABAergic inputs has been suggested to be the key mechanism responsible for several illicit drugs such as opioids, alcohol, and gamma hydroxybutyrate [18, $41,42]$. In the present study, we suggest that cannabinoids may use the same neural mechanism for their central action, which inhibits GABAergic neurotransmissions to the DRN, thus resulting in disinhibition of serotonergic neurons (disinhibition theory). This may explain our neurochemical data that 5 -HT efflux is elevated in the DRN-NAcc pathway following the systemic administration of exogenous cannabinoids.

We demonstrate that changes in 5-HT efflux are dependent not only on doses of cannabinoid injection but also on brain areas examined. Specifically, systemic injection produced approximately a $50-100 \%$ increase from baseline 5-HT in the NAcc. In contrast, there was an insignificant effect in the DRN following the same injection. The mechanism for the area-dependent efflux is not clearly understood but likely ascribed to regional circuits in the controlling of postsynaptic 5-HT efflux (see discussion further below) and also due to possible difference in the release of 5-HT in the two regions (see a review by [43]). The release of 5-HT from the serotonergic neurons is believed to take place at axon terminals where 5-HT-containing vesicles can be found. In the DRN, there are numerous recurrent axon collaterals projected from other raphe nuclei, by which serotonergic neurons can be negatively regulated [44]. Recent development of in vivo neurochemistry has suggested that dendrites are also equipped with 5-HTcontaining vesicles, and many neuroactive chemicals can influence a dendritic release $[45,46]$. This suggests that 5-HT efflux measured by microdialysis in the DRN is derived from many sources involved in distinct mechanisms including dendritic release, recurrent axon collateral release, and axon terminal release. Although it is difficult to determine the amounts of each release contributing to the 5-HT efflux in the DRN, it is conceivable that dendritic release may be an important component in the extracellular measurement. Much of available evidence suggests that the properties of dendritic release may be different from that at axons in the forebrain. For instance, the spontaneous 5-HT release is relatively higher in the DRN compared with that from axon terminals $[17,47]$. It is known that the receptor subtype expression is different between the somatodendritic sites and axon terminals of serotonergic neurons [15, 48]. Altogether, drugs that cause changes in 5-HT efflux at somatodendritic sites of the DRN would not necessarily produce the same response in forebrain areas that contain exclusively the axon terminals.

We found that the neurochemical response to cannabinoids is depending on the route of drug administration. Unlike systemic injection, local application of cannabinoids to the NAcc failed to produce the increase in 5-HT. Instead, 5-HT efflux was reduced (Figure 3(b)). It should be kept in mind that citalopram at the concentration of $1 \mu \mathrm{M}$ was added in the infusion medium into the NAcc. After the 


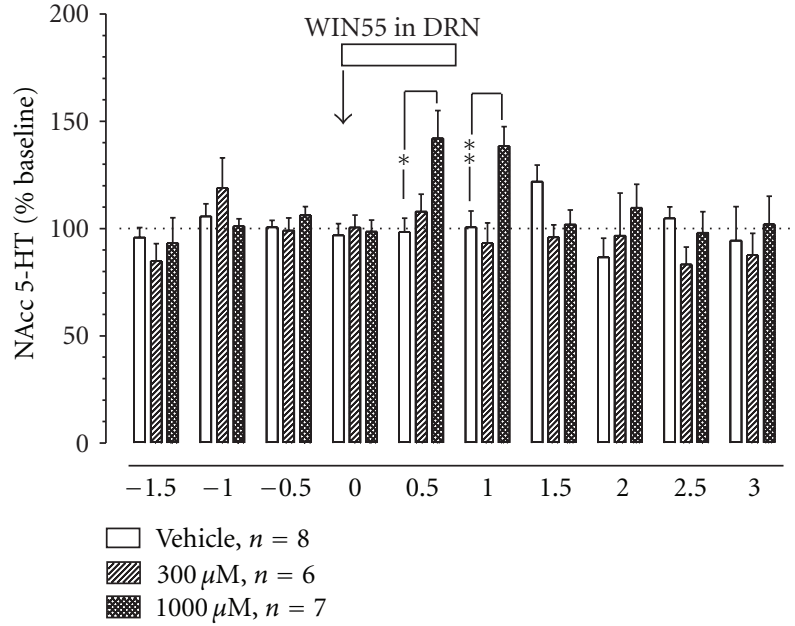

(a)

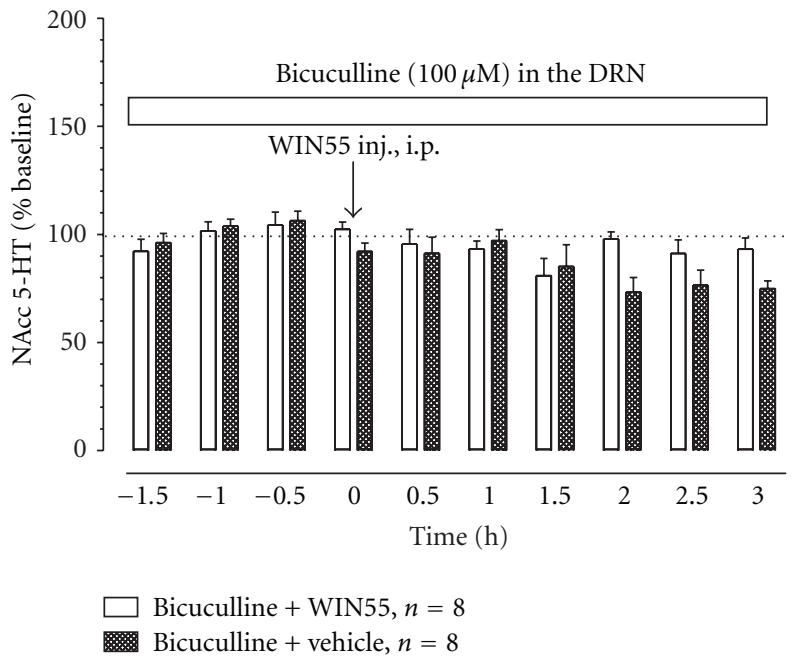

(b)

Figure 4: Data are expressed as percent of average baseline values ( $\%$ mean \pm s.e.m.). Mean baseline level of extracellular 5-HT was $0.39 \pm$ $0.06 \mathrm{pg} / \mathrm{sample}$ in the NAcc $(n=37)$. (a) Effect on 5-HT efflux in the NAcc of reverse dialysis infusion of WIN 55,212-2 in the DRN. The open horizontal bars indicate the 30-min period of drug infusion. WIN 55,212-2 (300 and $1000 \mu \mathrm{M})$ in the DRN produced a concentrationdependent increase in 5-HT efflux in the NAcc. ${ }^{*} P<0.05$ and ${ }^{* *} P<0.01$ versus vehicle examined by the repeated measures ANOVA followed by post hoc Scheffe test. (b) Effect on the WIN 55,212-2-induced increases in 5-HT efflux in the NAcc mediated by the reverse dialysis infusion of bicuculline $(100 \mu \mathrm{M})$ in the DRN. Systemic injection of WIN 55,212-2 at $5 \mathrm{mg} / \mathrm{kg}$ i.p. took place at time zero. Bicuculline pretreatment in the DRN blocked the systemic effect of WIN 55,212-2 on 5-HT efflux in the NAcc.

addition of citalopram, the basal level of 5-HT efflux before drug administration was elevated to $\sim 4 \mathrm{pg} / \mathrm{sample}$, almost 10 times greater than the physiological level. Since citalopram effectively blocks reuptake of extracellular 5-HT released from local circuitry, a small reduction in 5-HT efflux can be, therefore, sensitively determined. This pharmacological approach has been widely employed in the in vivo 5-HT research using microdialysis techniques. Furthermore, it has been demonstrated that a local application of citalopram at such a low concentration did not alter responsivity of serotonergic neurons to drug administration when the data were expressed as percentage changes relative to baseline [21]. For comparison, citalopram was also infused into the DRN for investigating the effects of cannabinoids on 5-HT efflux in the DRN. As a result, WIN55 caused a concentrationdependent increase in the DRN but a decrease in the NAcc. This further supports that neural circuits that control 5HT release in response to cannabinoids are different in two regions, regardless the addition of citalopram in the infusion medium. Previous in vitro studies demonstrated that cannabinoids decrease 5-HT release from axon terminals $[3,37]$. This effect can be ascribed to a direct inhibitory activation of CB1 receptors located on the axon terminals. Alternatively, excitatory presynaptic influence from glutamatergic afferents may be inhibited by cannabinoid application, as suggested in one study [36]. However, there is no evidence implicating that 5-HT axon terminal in this region is tonically controlled by glutamatergic afferents. Thus, reduction in 5-HT efflux can be considered to be a direct inhibitory effect of cannabinoids on serotonergic axon terminals as suggested in the previous studies $[23,37]$. This is consistent with the observation that $\mathrm{CB} 1$ receptors are expressed in the axon terminals that might directly respond to cannabinoids [9].

In the present study, we found that the local infusion of WIN55 into the DRN produced an increase in 5-HT in both the DRN and NAcc. These observations are in agreement with findings that excitatory stimulation of the DRN serotonergic cells results in an increase in extracellular $5-\mathrm{HT}$ in the NAcc $[49,50]$. Our data suggest that a CB1 receptor-mediated neural circuit that directly controls 5-HT release and transmission through the DRN-NAcc pathway would be activated by cannabinoids in the DRN. The effect was apparent in response to $300 \mu \mathrm{M}$ and $1000 \mu \mathrm{M}$, but not $100 \mu \mathrm{M}$ WIN55. In this regard, relatively high concentrations of WIN55 were used during the local infusion for two reasons. First, the microdialysis membrane served as a barrier to the region of the brain. It has been demonstrated with a $1-\mathrm{mm}$ microdialysis probe that only $\sim 7 \%$ of infused substances can cross the barrier as examined in an in vitro study [30]. Second, the viscosity of the organic solvent in which WIN55 was dissolved was relatively high, which might have dampened the diffusion of the drug across the probe membrane. Thus, it was necessary to utilize high concentrations in the infusion medium that drugs could effectively follow concentration gradients diffusing into local brain tissue.

Finally, we presented evidence that GABAergic neurotransmission in the DRN is the major neural target for cannabinoid regulation, which is responsible for changes in 5-HT efflux of the DRN-NAcc pathway. This view is strengthened by the observation that GABAergic neurons have 


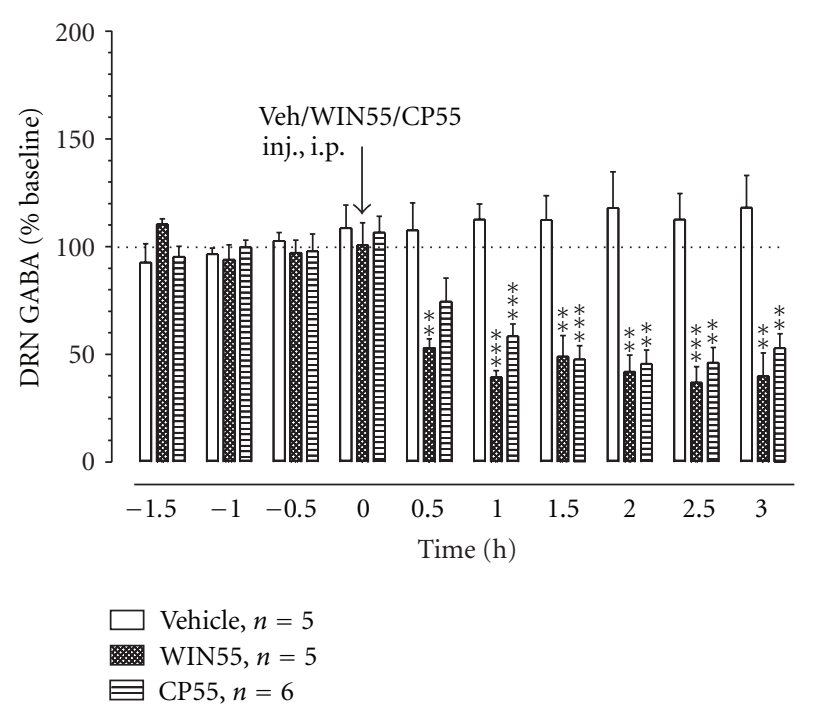

FIGURE 5: Effect of systemic cannabinoids on GABA efflux in the DRN. The arrow indicates the time of injection of $5 \mathrm{mg} / \mathrm{kg}$ WIN $55,212-2,0.5 \mathrm{mg} / \mathrm{kg}$ CP55940, or vehicle at $t=0$ minutes. Data are expressed as percent of average baseline values (\% mean \pm s.e.m.). Mean baseline level of extracellular GABA was $0.32 \pm$ $0.06 \mathrm{pmol} / \mathrm{sample}$. There was a significant reduction in GABA efflux in the DRN following systemic injection of WIN 55,212-2 or CP55945. ${ }^{*} P<0.05,{ }^{* *} P<0.01$, and ${ }^{* * *} P<0.001$ versus vehicle examined by the repeated measures ANOVA followed by post hoc Scheffe test.

a strong tonic inhibition on serotonergic neurons in the DRN $[17,49]$. Thus, although the action of cannabinoids in the circuit appears to have multiple sites including GABAergic and glutamatergic and serotonergic neurons $[6,39,51]$, the net consequence would be that serotonergic neurons are disinhibited resulting in an increase in 5-HT efflux in the regions receiving DRN projections. This hypothesis was experimentally approved in this study by testing with bicuculline, $\mathrm{a} \mathrm{GABA}_{\mathrm{A}}$ receptor antagonist, in which blocking GABA activation in the DRN abolished the increase in 5$\mathrm{HT}$ in the NAcc (Figure 4). Previous studies have shown that cannabinoids could reduce GABA efflux or GABAmediated spontaneously inhibitory postsynaptic currents in many brain regions including but not limited to frontal cortex, pallidus, substantia nigra, and hippocampus [52-55]. In the present study, we measured changes in GABA efflux in the DRN, demonstrating that the reduction in GABA efflux was in correlation with the increase in 5-HT efflux, further supporting the role of GABAergic neurotransmission in the DRN-NAcc serotonergic pathway. Collectively, systemic administration of cannabinoids may exert two opposite effects on serotonergic neurotransmission, resulting in a small increase in 5-HT efflux in the NAcc.

\section{Acknowledgments}

This work was supported by the NIH grant no. R15DA029863. The authors acknowledge the assistance of
Ellison Pearson and Nandini Rambahal in the neurochemical assay.

\section{References}

[1] V. D. P. Soares, A. C. Campos, V. C. D. Bortoli, H. Zangrossi, F. S. Guimarães, and A. W. Zuardi, "Intra-dorsal periaqueductal gray administration of cannabidiol blocks panic-like response by activating 5-HT1A receptors," Behavioural Brain Research, vol. 213, no. 2, pp. 225-229, 2010.

[2] T. V. Zanelati, C. Biojone, F. A. Moreira, F. S. Guimarães, and S. R. L. Joca, "Antidepressant-like effects of cannabidiol in mice: possible involvement of 5-HT1A receptors," British Journal of Pharmacology, vol. 159, no. 1, pp. 122-128, 2010.

[3] E. Schlicker and M. Kathmann, "Modulation of transmitter release via presynaptic cannabinoid receptors," Trends in Pharmacological Sciences, vol. 22, no. 11, pp. 565-572, 2001.

[4] M. Pistis, A. L. Muntoni, G. Pillolla, and G. L. Gessa, "Cannabinoids inhibit excitatory inputs to neurons in the shell of the nucleus accumbens: an in vivo electrophysiological study," European Journal of Neuroscience, vol. 15, no. 11, pp. 1795-1802, 2002.

[5] I. Wallmichrath and B. Szabo, "Analysis of the effect of cannabinoids on GABAergic neurotransmission in the substantia nigra pars reticulata," Naunyn-Schmiedeberg's Archives of Pharmacology, vol. 365, no. 4, pp. 326-334, 2002.

[6] S. Haj-Dahmane and R. Y. Shen, "Endocannabinoids suppress excitatory synaptic transmission to dorsal raphe serotonin neurons through the activation of presynaptic CB1 receptors," Journal of Pharmacology and Experimental Therapeutics, vol. 331, no. 1, pp. 186-196, 2009.

[7] E. Palazzo, V. de Novellis, S. Petrosino et al., "Neuropathic pain and the endocannabinoid system in the dorsal raphe: pharmacological treatment and interactions with the serotonergic system," European Journal of Neuroscience, vol. 24, no. 7, pp. 2011-2020, 2006.

[8] F. R. Bambico, N. Katz, G. Debonnel, and G. Gobbi, "Cannabinoids elicit antidepressant-like behavior and activate serotonergic neurons through the medial prefrontal cortex," Journal of Neuroscience, vol. 27, no. 43, pp. 11700-11711, 2007.

[9] M. Häring, G. Marsicano, B. Lutz, and K. Monory, "Identification of the cannabinoid receptor type 1 in serotonergic cells of raphe nuclei in mice," Neuroscience, vol. 146, no. 3, pp. 12121219, 2007.

[10] C. K. J. Lieben, H. W. M. Steinbusch, and A. Blokland, "5,7-DHT lesion of the dorsal raphe nuclei impairs object recognition but not affective behavior and corticosterone response to stressor in the rat," Behavioural Brain Research, vol. 168, no. 2, pp. 197-207, 2006.

[11] C. A. Lowry, M. W. Hale, A. K. Evans et al., "Serotonergic systems, anxiety, and affective disorder: focus on the dorsomedial part of the dorsal raphe nucleus," Annals of the New York Academy of Sciences, vol. 1148, pp. 86-94, 2008.

[12] S. Kusljic, J. Brosda, T. R. Norman, and M. van den Buuse, "Brain serotonin depletion by lesions of the median raphe nucleus enhances the psychotomimetic action of phencyclidine, but not dizocilpine (MK-801), in rats," Brain Research, vol. 1049, no. 2, pp. 217-226, 2005.

[13] W. Adams, S. Kusljic, and M. van den Buuse, "Serotonin depletion in the dorsal and ventral hippocampus: effects on locomotor hyperactivity, prepulse inhibition and learning and memory," Neuropharmacology, vol. 55, no. 6, pp. 1048-1055, 2008. 
[14] T. Sharp, L. Boothman, J. Raley, and P. Quérée, "Important messages in the "post": recent discoveries in 5-HT neurone feedback control," Trends in Pharmacological Sciences, vol. 28, no. 12, pp. 629-636, 2007.

[15] R. Tao and S. B. Auerbach, "Differential effect of NMDA on extracellular serotonin in rat midbrain raphe and forebrain sites," Journal of Neurochemistry, vol. 66, no. 3, pp. 1067-1075, 1996.

[16] R. Tao, Z. Ma, and S. B. Auerbach, "Influence of AMPA/ kainate receptors on extracellular 5-hydroxytryptamine in rat midbrain raphe and forebrain," British Journal of Pharmacology, vol. 121, no. 8, pp. 1707-1715, 1997.

[17] R. Tao and S. B. Auerbach, "Influence of inhibitory and excitatory inputs on serotonin efflux differs in the dorsal and median raphe nuclei," Brain Research, vol. 961, no. 1, pp. 109120, 2003.

[18] R. Tao and S. B. Auerbach, "GABAergic and glutamatergic afferents in the dorsal raphe nucleus mediate morphineinduced increases in serotonin efflux in the rat central nervous system," Journal of Pharmacology and Experimental Therapeutics, vol. 303, no. 2, pp. 704-710, 2002.

[19] G. Paxinos and C. Watson, Rat Brain Stereotaxic Coordinates, Academic Press, New York, NY, USA, 1998.

[20] Y. Qu, L. Arckens, F. Vandesande, and E. Vandenbussche, "Sampling extracellular aspartate, glutamate and $\gamma$ aminobutyric acid in striate cortex of awake cat by in vivo microdialysis: surgical and methodological aspects," Brain Research, vol. 866, no. 1-2, pp. 116-127, 2000.

[21] R. Tao, Z. Ma, and S. B. Auerbach, "Differential effect of local infusion of serotonin reuptake inhibitors in the raphe versus forebrain and the role of depolarization-induced release in increased extracellular serotonin," Journal of Pharmacology and Experimental Therapeutics, vol. 294, no. 2, pp. 571-579, 2000.

[22] F. Chaperon, P. Soubrié, A. J. Puech, and M. H. Thiébot, "Involvement of central cannabinoid (CB1) receptors in the establishment of place conditioning in rats," Psychopharmacology, vol. 135, no. 4, pp. 324-332, 1998.

[23] D. Moranta, S. Esteban, and J. A. García-Sevilla, "Differential effects of acute cannabinoid drug treatment, mediated by CB1 receptors, on the in vivo activity of tyrosine and tryptophan hydroxylase in the rat brain," Naunyn-Schmiedeberg's Archives of Pharmacology, vol. 369, no. 5, pp. 516-524, 2004.

[24] N. E. Kaminski, M. E. Abood, F. K. Kessler, B. R. Martin, and A. R. Schatz, "Identification of a functionally relevant cannabinoid receptor on mouse spleen cells that is involved in cannabinoid-mediated immune modulation," Molecular Pharmacology, vol. 42, no. 5, pp. 736-742, 1992.

[25] M. Rinaldi-Carmona, F. Barth, C. Congy et al., "SR147778 [5(4-bromophenyl)-1-(2,4-dichlorophenyl)-4-ethyl-N-(1- piperidinyl)-1H-pyrazole-3-carboxamide], a new potent and selective antagonist of the CB1 cannabinoid receptor: Biochemical and pharmacological characterization," Journal of Pharmacology and Experimental Therapeutics, vol. 310, no. 3, pp. 905-914, 2004.

[26] G. L. Gessa, S. Serra, G. Vacca, M. A. M. Carai, and G. Colombo, "Suppressing effect of the cannabinoid CB1 receptor antagonist, SR147778, on alcohol intake and motivational properties of alcohol in alcohol-preferring sP rats," Alcohol and Alcoholism, vol. 40, no. 1, pp. 46-53, 2005.

[27] J. Manzanares, J. Corchero, J. Romero, J. J. Fernández-Ruiz, J. A. Ramos, and J. A. Fuentes, "Pharmacological and biochemical interactions between opioids and cannabinoids," Trends in Pharmacological Sciences, vol. 20, no. 7, pp. 287-294, 1999.
[28] D. Viganò, T. Rubino, and D. Parolaro, "Molecular and cellular basis of cannabinoid and opioid interactions," Pharmacology Biochemistry and Behavior, vol. 81, no. 2, pp. 360-368, 2005.

[29] A. J. Tallett, J. E. Blundell, and R. J. Rodgers, "Endogenous opioids and cannabinoids: system interactions in the regulation of appetite, grooming and scratching," Physiology and Behavior, vol. 94, no. 3, pp. 422-431, 2008.

[30] R. Tao and S. B. Auerbach, "Involvement of the dorsal raphe but not median raphe nucleus in morphine-induced increases in serotonin release in the rat forebrain," Neuroscience, vol. 68, no. 2, pp. 553-561, 1995.

[31] C. Vásquez, R. Navarro-Polanco, G. Hernández et al., "Cannabinoids and dopamine receptors' action on calcium current in rat neurons," Canadian Journal of Neurological Sciences, vol. 32, no. 4, pp. 529-537, 2005.

[32] V. A. Mitchell, H. Kawahara, and C. W. Vaughan, "Neurotensin inhibition of GABAergic transmission via mGluRinduced endocannabinoid signalling in rat periaqueductal grey," Journal of Physiology, vol. 587, no. 11, pp. 2511-2520, 2009.

[33] S. Y. Zhang, M. Xu, Q. L. Miao, M. M. Poo, and X. H. Zhang, "Endocannabinoid-dependent homeostatic regulation of inhibitory synapses by miniature excitatory synaptic activities," Journal of Neuroscience, vol. 29, no. 42, pp. 13222-13231, 2009.

[34] R. J. McLaughlin and G. Gobbi, "Cannabinoids and emotionality: a neuroanatomical perspective," The Journal of Neuroscience, vol. 204, pp. 134-144, 2012.

[35] G. Ferraro, M. E. Montalbano, P. Sardo, and V. La Grutta, "Lateral habenular influence on dorsal raphe neurons," Brain Research Bulletin, vol. 41, no. 1, pp. 47-52, 1996.

[36] K. Sano, K. Mishima, E. Koushi et al., " $\Delta \Delta^{9}$-Tetrahydrocannabinol-induced catalepsy-like immobilization is mediated by decreased 5-HT neurotransmission in the nucleus accumbens due to the action of glutamate-containing neurons," Neuroscience, vol. 151, no. 2, pp. 320-328, 2008.

[37] M. Nakazi, U. Bauer, T. Nickel, M. Kathmann, and E. Schlicker, "Inhibition of serotonin release in the mouse brain via presynaptic cannabinoid CB1 receptors," Naunyn-Schmiedeberg's Archives of Pharmacology, vol. 361, no. 1, pp. 19-24, 2000.

[38] N. Egashira, K. Mishima, S. Katsurabayashi et al., "Involvement of 5-hydroxytryptamine neuronal system in $\Delta 9$ tetrahydrocannabinol-induced impairment of spatial memory," European Journal of Pharmacology, vol. 445, no. 3, pp. 221-229, 2002.

[39] G. Gobbi, F. R. Bambico, R. Mangieri et al., "Antidepressantlike activity and modulation of brain monoaminergic transmission by blockade of anandamide hydrolysis," Proceedings of the National Academy of Sciences of the United States of America, vol. 102, no. 51, pp. 18620-18625, 2005.

[40] E. S. Levine and B. L. Jacobs, "Neurochemical afferents controlling the activity of serotonergic neurons in the dorsal raphe nucleus: microiontophoretic studies in the awake cat," Journal of Neuroscience, vol. 12, no. 10, pp. 4037-4044, 1992.

[41] A. Brancucci, N. Berretta, N. B. Mercuri, and W. Francesconi, "Presynaptic modulation of spontaneous inhibitory postsynaptic currents by gamma-hydroxybutyrate in the substantia nigra pars compacta," Neuropsychopharmacology, vol. 29, no. 3, pp. 537-543, 2004.

[42] F. Jia, D. Chandra, G. E. Homanics, and N. L. Harrison, "Ethanol modulates synaptic and extrasynaptic GABAA receptors in the thalamus," Journal of Pharmacology and Experimental Therapeutics, vol. 326, no. 2, pp. 475-482, 2008. 
[43] A. Adell, P. Celada, M. T. Abellán, and F. Artigas, "Origin and functional role of the extracellular serotonin in the midbrain raphe nuclei," Brain Research Reviews, vol. 39, no. 2-3, pp. 154 180, 2002.

[44] R. McQuade and T. Sharp, "Functional mapping of dorsal and median raphe 5-hydroxytryptamine pathways in forebrain of the rat using microdialysis," Journal of Neurochemistry, vol. 69, no. 2, pp. 791-796, 1997.

[45] F. Bergquist, H. S. Niazi, and H. Nissbrandt, "Evidence for different exocytosis pathways in dendritic and terminal dopamine release in vivo," Brain Research, vol. 950, no. 1-2, pp. 245-253, 2002.

[46] M. Ludwig, N. Sabatier, P. M. Bull, R. Landgraf, G. Dayanithi, and G. Leng, "Intracellular calcium stores regulate activitydependent neuropeptide release from dendrites," Nature, vol. 418, no. 6893, pp. 85-89, 2002.

[47] D. Becquet, M. Faudon, and F. Hery, "The role of serotonin release and autoreceptors in the dorsalis raphe nucleus in the control of serotonin release in the cat caudate nucleus," Neuroscience, vol. 39, no. 3, pp. 639-647, 1990.

[48] J. L. Lukkes, G. L. Forster, K. J. Renner, and C. H. Summers, "Corticotropin-releasing factor 1 and 2 receptors in the dorsal raphé differentially affect serotonin release in the nucleus accumbens," European Journal of Pharmacology, vol. 578, no. 2-3, pp. 185-193, 2008.

[49] R. Tao and S. B. Auerbach, "Regulation of serotonin release by GABA and excitatory amino acids," Journal of Psychopharmacology, vol. 14, no. 2, pp. 100-113, 2000.

[50] Z. Ma, E. Pearson, and R. Tao, "CART peptides increase 5hydroxytryptamine in the dorsal raphe and nucleus accumbens of freely behaving rats," Neuroscience Letters, vol. 417, no. 3, pp. 303-307, 2007.

[51] A. Mendiguren and J. Pineda, "Effect of the CB1 receptor antagonists rimonabant and AM251 on the firing rate of dorsal raphe nucleus neurons in rat brain slices," British Journal of Pharmacology, vol. 158, no. 6, pp. 1579-1587, 2009.

[52] P. K. Y. Chan and W. H. Yung, "Occlusion of the presynaptic action of cannabinoids in rat substantia nigra pars reticulata by cadmium," Neuroscience Letters, vol. 249, no. 1, pp. 57-60, 1998.

[53] N. Hájos, I. Katona, S. S. Naiem et al., "Cannabinoids inhibit hippocampal GABAergic transmission and network oscillations," European Journal of Neuroscience, vol. 12, no. 9, pp. 3239-3249, 2000.

[54] L. Ferraro, M. C. Tomasini, T. Cassano et al., "Cannabinoid receptor agonist WIN 55,212-2 inhibits rat cortical dialysate $\gamma$-aminobutyric acid levels," Journal of Neuroscience Research, vol. 66, no. 2, pp. 298-302, 2001.

[55] S. Caillé and L. H. Parsons, "Cannabinoid modulation of opiate reinforcement through the ventral striatopallidal pathway," Neuropsychopharmacology, vol. 31, no. 4, pp. 804-813, 2006. 

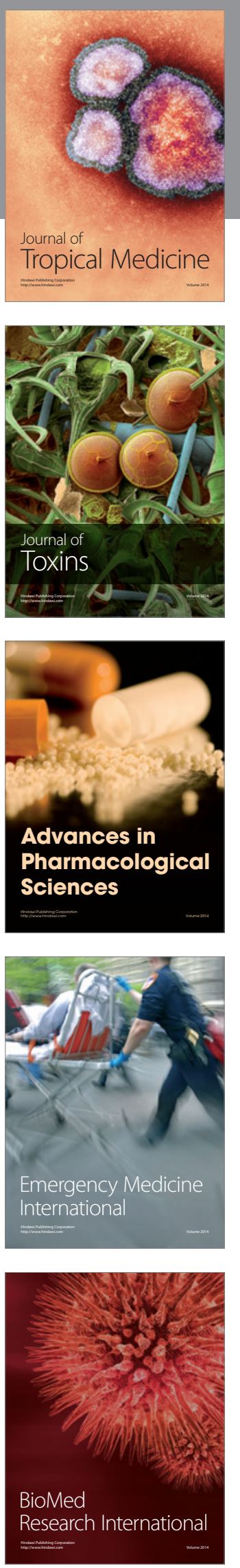
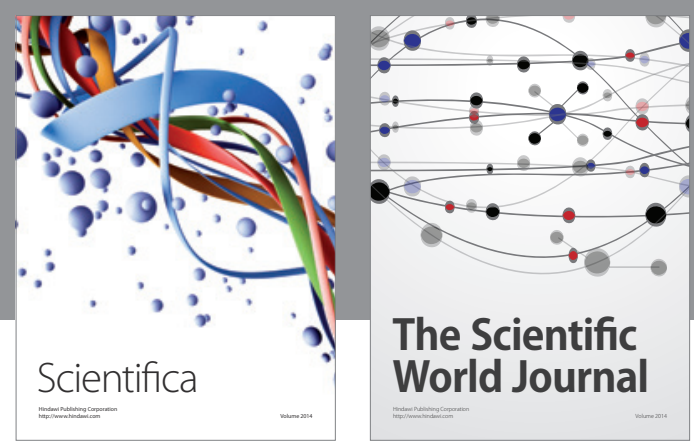

The Scientific World Journal
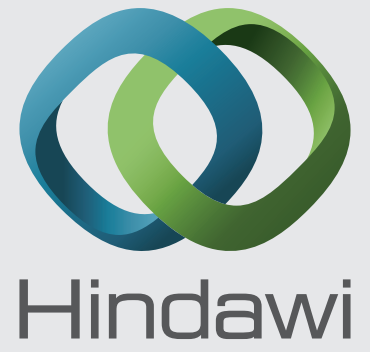

Submit your manuscripts at

http://www.hindawi.com
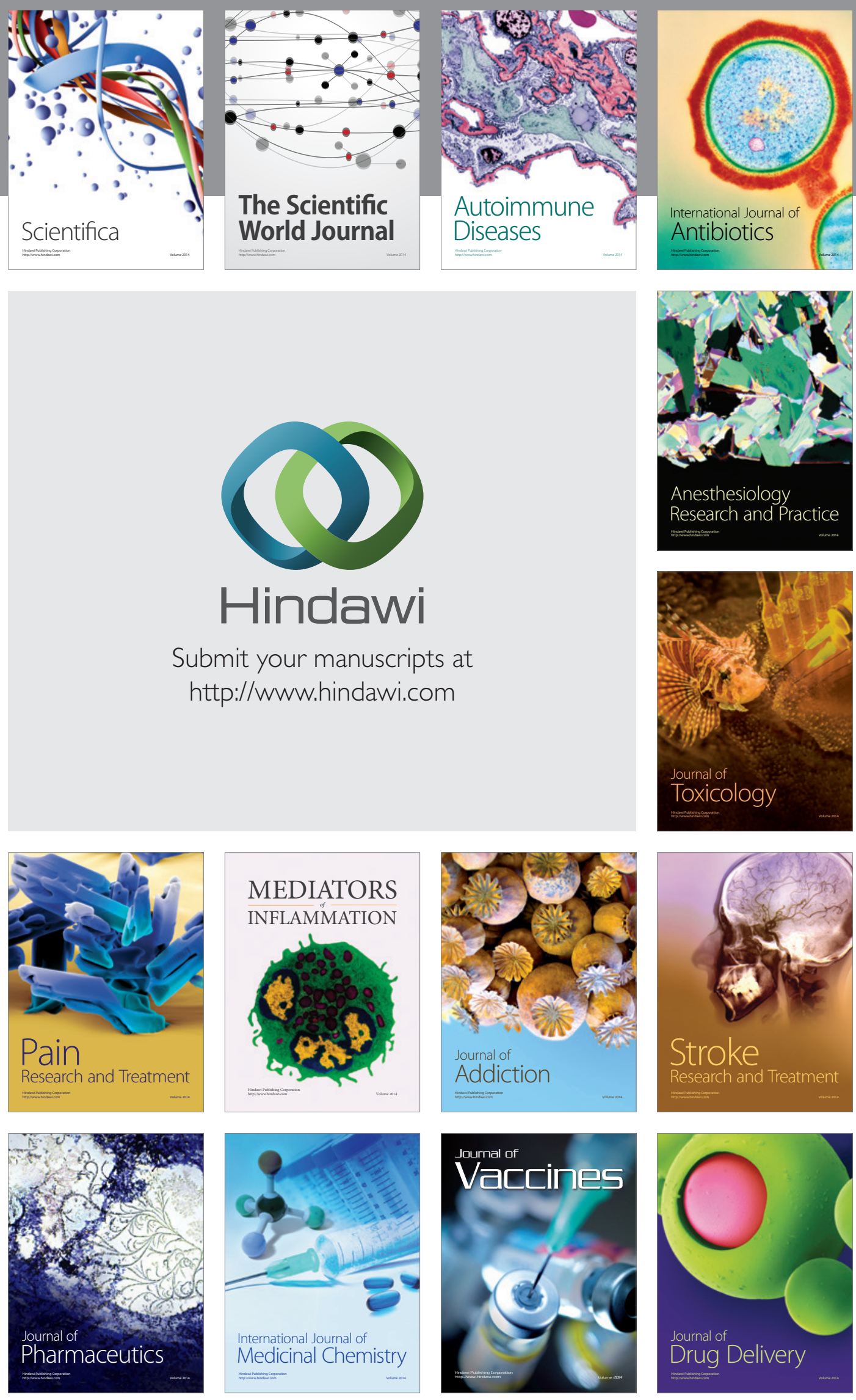